\title{
Localized Expression of Cathepsin B-like Sequences from Root Nodules of Pea (Pisum sativum)
}

\author{
Jason L. Vincent, Preeti Dahiya, and Nicholas J. Brewin \\ Department of Genetics, John Innes Centre, Norwich Research Park, Colney Lane, Norwich, NR4 7UH, \\ U.K. \\ Accepted 5 April 2000.
}

\begin{abstract}
Cathepsin B is an ancient family of eukaryotic cysteine proteases. We describe PsCat1, a plant cathepsin B-like transcript, identified as an expressed sequence in Rhizobium-induced, nitrogen-fixing root nodules of pea. In situ hybridization studies in root nodules showed strong, extremely localized expression of PsCat1 in individual cells associated with the central infected tissue. Restriction fragment polymorphism mapping of the PsCat1 locus in pea shows no correlation with existing mutant lines defective in symbiosis.
\end{abstract}

Additional keywords: hypersensitive response, nitrogen fixation, nodulins.

The cathepsin B proteases were originally identified in mammalian systems as lysosomal, hydrolytic enzymes. Because they can degrade a wide range of peptide/protein substrates, a role in cellular protein turnover has been indicated (Bond and Butler 1987). Investigations of tumorigenesis have indicated a critical role in mammalian cancer development (for a review see Elliott and Sloane 1996). In such malignancies it is thought that the extracellular presence of the protease aids matrix degradation. More recently, a role for cathepsin B has been demonstrated in cellular apoptosis, where it activates caspase-11 by processing the pro-form, and can also directly induce nuclear apoptosis (Vancompernolle et al. 1998).

To date, there have been few reports of cathepsin B-like sequences in plants (Ward et al. 1997). A gibberellin-responsive mRNA was isolated from wheat and was subsequently shown to be expressed in the scutellar parenchyma of embryos and in the aleurone layer, but not in roots (Cejudo et al. 1992). In Nicotiana rustica, a wounding-responsive mRNA was isolated from roots and was shown to be expressed in most plant organs (Lidgett et al. 1995).

A cDNA corresponding to cathepsin B was obtained serendipitously by rapid amplification of $3^{\prime}$ cDNA ends (3' RACE; Frohman et al. 1988) with pea root nodule polyA ${ }^{+}$mRNA as a template and degenerate primers designed against a motif unrelated to cathepsin sequences. Upon sequence analysis, one

Corresponding author: N. J. Brewin; E-mail: nick.brewin@bbsrc.ac.uk

Nucleotide and/or amino acid sequence data can be found at the EMBL data base as accession nos. AJ251534 (clone A6), AJ251535 (clone A7), AJ251536 (PsCat1). of the amplification products, approximately $800 \mathrm{bp}$, showed high homology to the cathepsin B genes, especially to cathepsin B-like sequences of $N$. rustica and Triticum aestivum (Lidgett et al. 1995; Cejudo et al. 1992). This cDNA was named PsCat1 (Pisum sativum cathepsin clone 1 ).

The spatial expression of PsCat1 in the mature root nodule of pea was investigated by in situ hybridization. Pea nodules were harvested at 3 weeks post inoculation with Rhizobium leguminosarum bv. viciae 3841, fixed in $4 \%$ formaldehyde in phosphate-buffered saline, and embedded in paraffin wax as described by Jackson (1991). Longitudinal nodule sections of $8 \mu \mathrm{m}$ thickness were prepared with a Jung microtome (Heidelberg, Germany), and attached to $\gamma$-aminopropyltriethoxysilane-treated (APTES; Sigma, Poole, UK) glass microscope slides. In situ hybridization was carried out as described by Gardner et al. (1996) with digoxigenin-labeled riboprobes prepared from linearized plasmids carrying sense and antisense PsCat 1 inserts primed by the T7 promoter. Figure 1 shows the results of sense and antisense hybridizations, and illustrates a distinctive spatial pattern of PsCat1 expression in the root nodule. There was no expression in the nodule apex but high levels of transcript were seen to be associated with vacuolated (apparently uninfected) cells in a region of the nodule that begins with and extends from the interzone II/III into zone III proper. Infected cells in this region have been shown to express the early nodulins ENOD3 and ENOD12 (Scheres et al. 1990) as the bacteroids that they contain develop the capacity for nitrogen fixation (Vasse et al. 1990; Brewin 1991). No PsCat1 transcript was detectable in zone IV, a zone of the nodule that sees the onset of senescence of the spent cells from zone III.

If PsCatl activity is induced in the transition zone II/III, it may correspond with a change of cell activity. For example, it is possible that a cathepsin B-like protease may be engaged in the controlled proteolytic cascade required to degrade redundant proteins and recycle amino acids with which the cell can manufacture different proteins required in the new, nitrogenfixing, cell state. Alternatively, given the wealth of information that reports extracellular localizations of cathepsin B, it is possible that PSCAT1 has an extracytoplasmic role in the rhizobial invasion process. However, in situ hybridization patterns of PsCat1 transcript in the root nodule do not include zone II, the zone of invasion (Brewin 1991). Another possibility is that PsCAT1 is involved in some form of apoptotic 

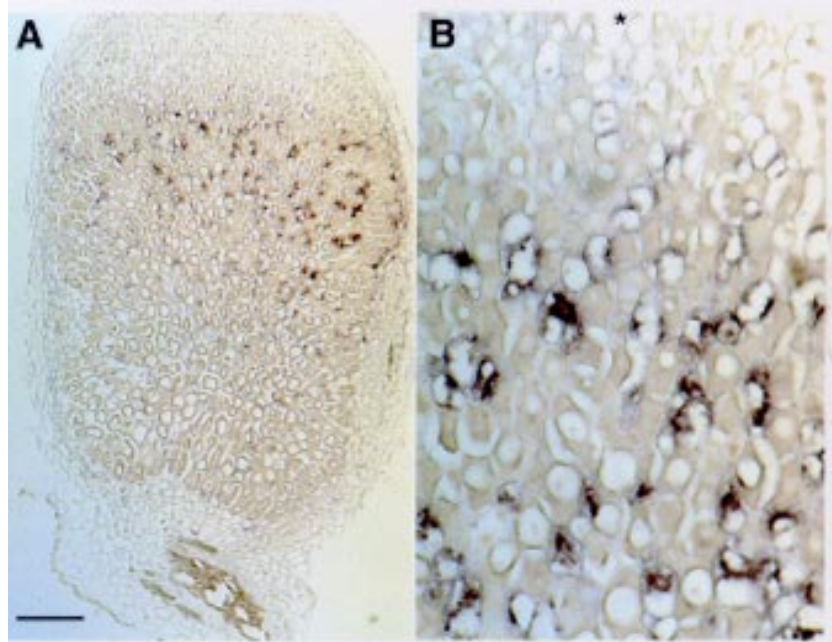

C

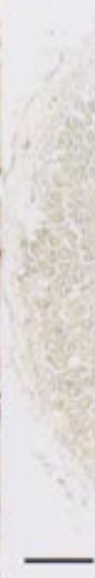

D

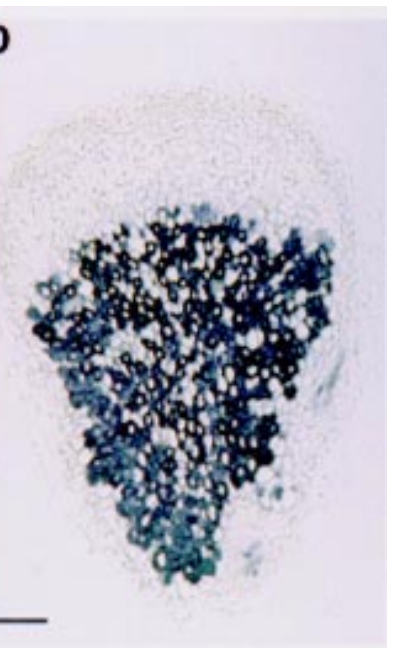

Fig. 1. Longitudinal sections of mature pea root nodules induced by Rhizobium spp. and probed with riboprobes to show in situ localization of transcripts. A, Antisense PsCat1 probe showing strong signal (black coloration) starting in the interzone and extending into zone III. B, Enlargement of A, illustrating presence of signal in distinct cells of zones II/III and III, but not zone II (asterisk). C, Sense PsCat1 probe showing no signal, only low levels of background staining enabling general nodule structure to be seen. D, Antisense PsNlec1 probe (Kardailsky et al. 1996), showing strong signal associated with the entire central, infected tissue of the nodule. Bars $=200 \mu \mathrm{m}$.

Fig. 2. A, Autoradiographic image of a Southern blot of EcoRI-digested genomic DNA from two parental pea varieties after labeling with a PsCat1 radioprobe. The restriction fragment length polymorphism used as a marker with which to score segregation of PsCatl is indicated by black arrowheads to the side of the image. Parental DNA is from JI15 and JI399. B, A diagram of linkage group V of pea, to which PsCat1 has been mapped (courtesy of T. H .N. Ellis, John Innes Centre, UK).

response to rhizobial infection in those cells seen to express the transcript (Vancompernolle et al. 1998). Similar distributions have recently been observed for in situ hybridizations with a peroxidase cDNA in clover nodules (Crockard et al. 1999; M. A. Crockard and J. E. Cooper, personal communication) and a PR1-related cDNA in pea root nodules (P. Dahiya, unpublished observations), leading to the interesting possibility that a minority of cells in the central infected tissue undergo the equivalent of the micro-hypersensitive response (Alvarez et al. 1998). However, it is still unclear whether all the cells exhibiting PsCatl activity are uninfected or whether some are sparsely infected (Fig. 1), and whether these cells subsequently senesce.

To complete the PsCat 1 cDNA sequence, $5^{\prime}$ RACE was applied, with nested primers specific to the PsCat1 cDNA and nodule polyA ${ }^{+}$mRNA. The reverse primer in the first round of PCR was JLV22 (5' GGG AGT TTG ATA TCC TGG C 3') and the reverse primer in the second round was JLV23 $\left(5^{\prime}\right.$ CAC AAC CAG GAT GAG AAC ATC C 3'). Two products, approximately $600 \mathrm{bp}$ (clone A6) and approximately $700 \mathrm{bp}$ (clone A7), were cloned and sequenced. Both products exhibited $100 \%$ homology at the $3^{\prime}$ ends; however, this homology dropped markedly in the regions 120 and $240 \mathrm{bp}$ from the $5^{\prime}$ ends of the sequences, respectively. Translation of either $5^{\prime}$ RACE product does not identify in-frame translation start codons that would correspond to equivalent start sequences of other cathepsin B proteins, but the reading frames identified do extend $5^{\prime}$ without encountering stop codons. It is therefore possible that the products amplified were primed from de-

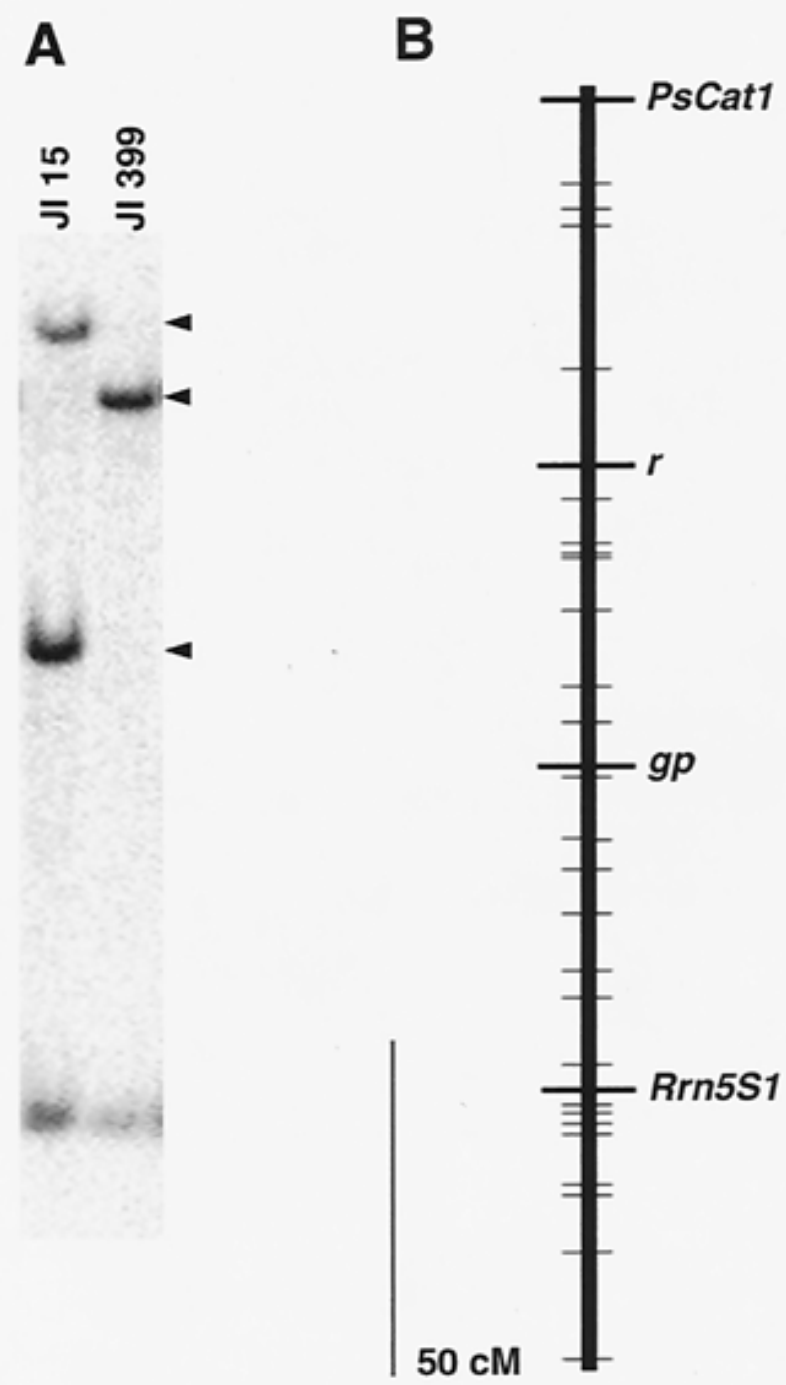

Vol. 13 , No. $7,2000 / 779$ 
graded transcripts, where the $5^{\prime}$ ends no longer extend to the transcriptional starts. Thus, the as-yet-unidentified start codons may reside slightly further upstream of the sequences analyzed here. In support of this hypothesis is the strong hydrophobic nature of the deduced amino termini from both $5^{\prime}$ RACE cDNAs, indicating the existence of putative signal peptide domains. The divergent $5^{\prime}$ ends of the two $5^{\prime}$ RACE products may result from transcription of separate yet related genes. Alternatively, divergence of transcripts in a specific region may be explained by altered splicing patterns of primary transcripts from the same gene. It has been noted in the studies of human cancer that the cathepsin B transcript is sometimes alternatively spliced to produce truncated versions of the gene product, which may be targeted differently within the cell (Elliott and Sloane 1996). The isolation of genomic clones will allow these questions to be addressed.

To map the PsCat1 locus, Southern blots of genomic DNA (digested with EcoRI) from pea parental lines JI15 and JI399, and the $F_{11}$ recombinant inbred (RI) progeny resulting from crossing these lines (Ellis et al. 1992), were probed with a random-primed, ${ }^{32} \mathrm{P}$-labeled, PsCat1 probe generated with the Boehringer Hexanucleotide $10 \times$ Mix (Boehringer-Ingelheim, Mannheim, Germany). Hybridization was performed overnight at $65^{\circ} \mathrm{C}$ and the blot was washed twice in $0.1 \times \mathrm{SSC}(1 \times$ $\mathrm{SSC}$ is $0.15 \mathrm{M} \mathrm{NaCl}$ plus $0.015 \mathrm{M}$ sodium citrate) $/ 0.3 \%$ sodium dodecyl sulfate (SDS) at $60^{\circ} \mathrm{C}$ before it was exposed to a phosphoimaging plate (Fuji, London). Figure 2A shows the restriction fragment length polymorphic (RFLP) marker used to score segregation for PsCatl in the $\mathrm{F}_{11}$ progeny of the RI population. Linkage relationships were calculated with MapMaker version 3.0 software (Whitehead Inst., Cambridge, MA; Lander et al. 1987). Figure 2B shows the position of the PsCat1 locus at an end of linkage group V of the pea RFLP map (Hall et al. 1997; Laucou et al. 1998). Allocation of a map position for PsCatl does not correlate with previously mapped lesions in pea.

The study of PsCatl activity in the root nodule will be further advanced by immunolocalization to identify whether this protease is indeed "lysosomal" or extracellular in nature, or, whether it is associated with degrading cells/nuclei.

\section{ACKNOWLEDGMENTS}

We wish to thank I. Iturbe-Ormateaxe for technical advice regarding in situ hybridization, J.-P. Wisniewski for providing the PsNlec probe, and M. R. Knox and T. H. N. Ellis for assistance with RFLP mapping of PsCat1. J. L. V. thanks the GB-BBSRC for a postgraduate studentship.

\section{LITERATURE CITED}

Alvarez, M. E., Pennell, R. I., Meijer, P. J., Ishikawa, A., Dixon, R. A., and Lamb, C. 1998. Reactive oxygen intermediates mediate a sys- temic signal network in the establishment of plant immunity. Cell 92: 773-784.

Bond, J. S., and Butler, P. E. 1987. Intracellular proteases. Annu. Rev. Biochem. 56:333-364.

Brewin, N. J. 1991. Development of the legume root nodule. Annu. Rev. Cell. Biol. 7:191-226.

Cejudo, F. J., Murphy, G., Chinoy, C., and Baulcombe, D. C. 1992. A gibberellin-regulated gene from wheat with sequence homology to cathepsin B of mammalian cells. Plant J. 2:937-948.

Crockard, M. A., Bjourson, A. J., and Cooper, J. E. 1999. A new peroxidase cDNA from white clover: Its characterization and expression in root tissue challenged with homologous rhizobia, heterologous rhizobia, or Pseudomonas syringae. Mol. Plant-Microbe Interact. 12:825828.

Elliott, E., and Sloane, B. F. 1996. The cysteine protease cathepsin B in cancer. Perspect. Drug Discovery Design 6:12-32.

Ellis, T. H. N., Turner, L., Hellens, R. P., Lee, D., Harker, C. L., Enard, C., Domoney, C., and Davies, D. R. 1992. Linkage maps in pea. Genetics 130:649-663.

Frohman, M. A., Dush, M. K., and Martin, G. R. 1988. Rapid production of full-length cDNAs from rare transcripts - amplification using a single gene-specific oligonucleotide primer. Proc. Natl. Acad. Sci. USA 85:8998-9002.

Gardner, C. D., Sherrier, D. J., Kardailsky, I. V., and Brewin, N. J. 1996. Localization of lipoxygenase proteins and mRNA in pea nodules: Identification of lipoxygenase in the lumen of infection threads. Mol. Plant-Microbe Interact. 9:282-289.

Hall, K. J., Parker, J. S., Ellis, T. H. N., Turner, L., Knox, M. R., Hofer, J. M. I., Lu, J., Ferrandiz, C., Hunter, P. J., Taylor, J. D., and Baird, K. 1997. The relationship between genetic and cytogenetic maps of pea .2. Physical maps of linkage mapping populations. Genome 40:755769.

Jackson, D. P. 1991. In situ hybridization in plants. Pages 157-181 in: Molecular Plant Pathology: A Practical Approach. D. J. Bowles, S. J. Gurr, and M. McPherson, eds. Oxford University Press, Oxford.

Kardailsky, I. V., Sherrier, D. J., and Brewin, N. J. 1996. Identification of a new pea gene, PsNlec1, encoding a lectin-like glycoprotein isolated from the symbiosomes of root nodules. Plant Physiol. 111:49-60.

Lander, E. S., Green, P., Abrahamson, J., Barlow, A., Daly, M. J., Lincoln, S. E., and Newburg, L. 1987. MapMaker: An interactive computer package for constructing primary genetic linkage maps of experimental and natural populations. Genomics 1:174-181.

Laucou, V., Haurogne, K., Ellis, N., and Rameau, C. 1998. Genetic mapping in pea. 1. RAPD-based genetic linkage map of Pisum sativum. Theoret. Appl. Genet. 97:905-915.

Lidgett, A. J., Moran, M., Wong, K. A. L., Furze, J., Rhodes, M. J. C., and Hamill, J. D. 1995. Isolation and expression pattern of a cDNA encoding a cathepsin B-like protease from Nicotiana rustica. Plant Mol. Biol. 29:379-384.

Scheres, B., Van Engelen, F. van der Knaap, E. Van der Wiel, C., van Kammen, A., and Bisseling, T. 1990. Sequential induction of nodulin gene expression in the developing pea nodule. Plant Cell 2:687-700.

Vancompernolle, K., VanHerreweghe, F., Pynaert, G., VandeCraen, M., Devos, K., Totty, N., Sterling, A., Fiers, W., Vandenabeele, P., and Grooten, J. 1998. Atractyloside-induced release of cathepsin B, a protease with caspase-processing activity. FEBS Lett. 438:150-158.

Vasse, J., deBilly, F., Camut, S., and Truchet, G. 1990. Correlation between ultrastructural differentiation of bacteroids and nitrogenfixation in alfalfa nodules. J. Bacteriol. 172:4295-4306.

Ward, W., Alvarado, L., Rawlings, N. D., Engel, J. C., Franklin, C., and McKerrow, J. H. 1997. A primitive enzyme for a primitive cell: The protease required for excystation of Giardia. Cell 89:437-444. 